\title{
The Development of Chinese B2C Cross-border E-Commerce-Taking Wish Platform as an Example
}

\author{
TING WANG ${ }^{1,2, a}$, ZHENLONG PENG ${ }^{1,2, *, b}$, ManPing Ye 1,2,c $^{\text {, }}$ \\ ${ }^{1}$ Chen Shouren Business School, Quanzhou Normal University, Quanzhou 362000, China \\ ${ }^{2}$ High Educational Engineering Research Center of Fujian Province for E-Commerce Intelligent Based on Cloud Computing and \\ Internet of Things, Quanzhou 362000, China \\ a15860303135@163.com, bjxndpzl@163.com, ${ }^{\mathrm{c} 375734043 @ q q . c o m}$ \\ *Corresponding author
}

\begin{abstract}
Cross-border e-commerce has developed rapidly in recent years and has become a new force to promote China's economic development. Focusing on B2C cross-border e-commerce, the paper firstly introduces the concept of B2C cross-border e-commerce, analyzes its current situation and the influence of B2Cexport cross-border e-commerce on China's small and medium-sized enterprises (SMEs). Then it sorts out the development and explains the features and advantages of the Wish platform. After that, it puts forward some suggestions on how to operate on the Wish platform as well as the operation process. Finally, a conclusion is reached that $\mathrm{B} 2 \mathrm{C}$ cross-border e-commerce has good prospects for development, and it has promoted B2C cross-border e-commerce. SMSEs should seize the development opportunity.
\end{abstract}

Keywords-Wish Platform; Personalization Recommendation; E-Commerce; B2C Cross-border

\section{INTRODUCTION}

\section{A. B2C Cross-border E-Business}

Cross-border E-Business refers to the subject of transactions among different countries and regions. According to the different objects of the transaction, cross-border e-commerce can be divided into Business to Business (B2B), Business to Customer (B2C) to Customer, Individual to Individual), an international commercial activity that transacts, pays and settles cross-border logistics of goods through cross-border e-commerce platforms and completes the series of trade transactions[1]. Among them, B2C cross-border e-commerce, i.e. cross-border e-commerce between enterprises and consumers, which is mainly applied to enterprises that sell directly to consumers in a global scale. Cross-border e-commerce can be divided into self-operated B2C and third party B2C from the operating mode.

At present, Alibaba AliExpress is the representative of China's third-party B2C cross-border e-commerce. There are also foreign Amazon, eBay, etc., they also have a strong influence in the international. In recent years, the third-party B2C platform 'Wish', which is based on the mobile terminal, has emerged rapidly and has shown strong development momentum. The third-party B2C cross-border e-commerce platform is the mainstream model, which has effectively promoted the development of small and medium-sized foreign trade enterprises.

\section{B. Development of B2C Cross-border E-commerce in China}

With the development of mobile Internet technology and logistics, the global space and distance has become shorter. China is a big manufacturing country. Therefore, cross-border e-commerce has a good development foundation. In particular, in recent years, China has introduced a number of preferential policies conducive to the development of B2C cross-border e-commerce, and the third-party B2C cross-border e-commerce platform has developed rapidly. It has had a greater impact on China's foreign trade [2].

\section{1) Scale of development}

According to statistics, more than 1 million companies have completed registrations on major $\mathrm{B} 2 \mathrm{C}$ cross-border e-commerce platforms, of which the proportion of SMEs has reached more than 95\%. In 2016, China's cross-border e-commerce transactions totaled 6.7 trillion yuan, of which B2C cross-border e-commerce transactions amounted to 1.25 trillion yuan, and exports reached 944 billion yuan, of which SMEs accounted for $90 \%$ of the transaction share, reaching 47.8. \%. SMEs have become a major part of B2C cross-border e-commerce development.

\section{2) Types of goods}

According to the statistics of China's E-Commerce Research Center, in 2016, China's exports of cross-border products are dominated by $3 \mathrm{C}$ electronic products, where $3 \mathrm{C}$ accounts for $37.7 \%$, clothing accounts for $10.2 \%$ and outdoor products accounts for $7.5 \%$ etc. The details are as shown in Figure 1. 3C products are still the main products for cross-border exports, mainly because they are easy to store and transport, have a good cost advantage, and are very suitable for sale on the Internet. In fact, the key reason why China's export cross-border e-commerce can dominate the foreign market is the high cost performance of the products. However, as China's labor costs gradually increase, the cost advantage gradually disappears. Therefore, cross-border exports should increase the added value of products, increase the pricing flexibility of the B-end, and enrich the product categories as much as possible. 


\section{Distribution of cross-border e-commerce export categories in}

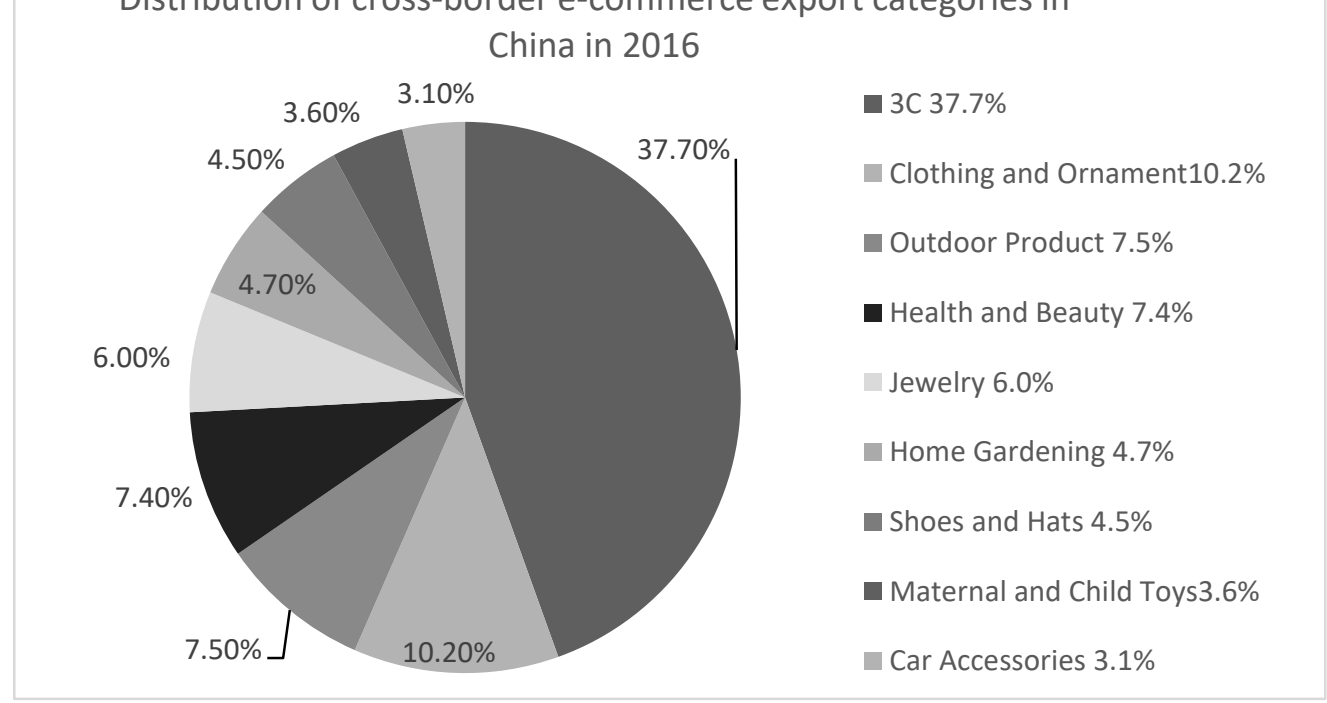

Fig. 1 Distribution of Cross-border Commodities in China in 2016

\section{3) Trading scale}

According to the 2016-2017 China Cross-border E-Commerce Market Research Report released by Ai Media Consulting, the total cross-border e-commerce transactions in China reached 6.7 trillion yuan in 2016, and the total cross-border transactions in China from 2012 to 2017 [ 3], the details are shown in Figure 2. Based on this speed, the transaction size in 2018 is likely to reach 8.8 trillion yuan. Cross-border export of e-commerce has become an important engine for promoting the development of China's foreign trade.

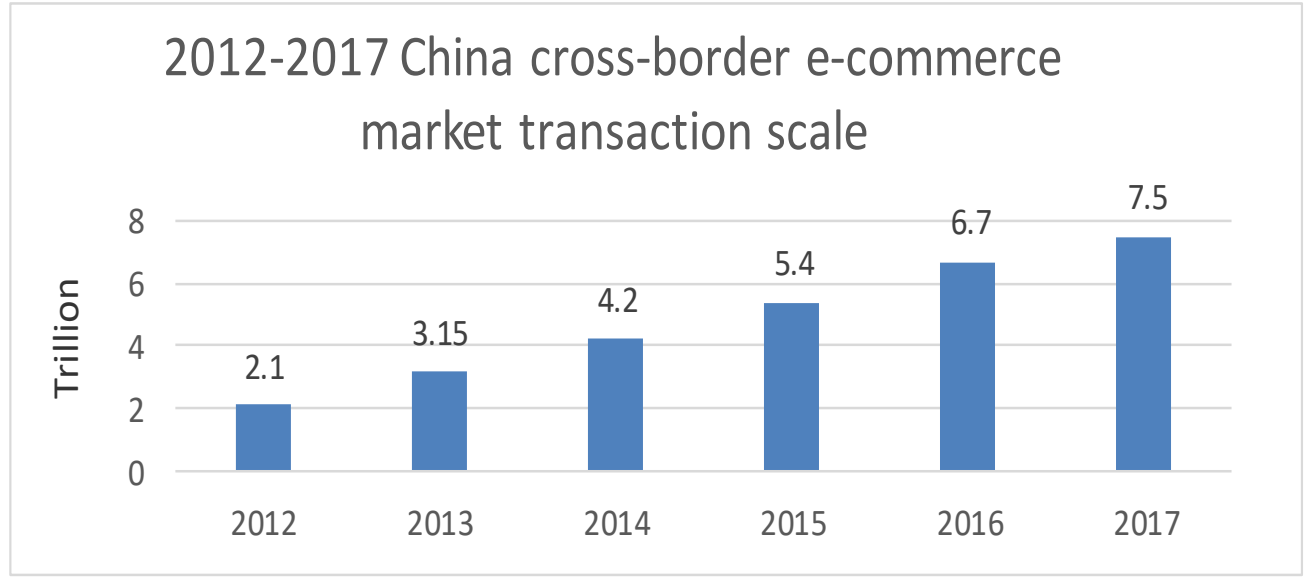

Fig. 2 2012-2017 China Cross-border E-commerce Market Size

According to the AliChina Research Institute's 2016 China Cross-Border E-Commerce Development Report, China's B2C cross-border e-commerce transaction volume reached 751.2 billion yuan in 2016, a year-on-year increase of $43 \%$. The export volume reached 503.2 billion yuan, a year-on-year increase of 36\%. According to the "Report on China's Foreign Trade Situation (Autumn 2017)" by the Ministry of Commerce in November 2017, the scale of China's export cross-border e-commerce transactions in the first half of 2017 was 2.75 trillion yuan, a year-on-year increase of $31.5 \%$. Only $15 \%$ ). It is estimated that by 2020, China's B2C cross-border e-commerce exports will reach 2.16 trillion yuan, an average annual increase of about $34 \%$ [4]. China is expected to become the world's largest B2C cross-border e-commerce export market, covering 943 million consumers worldwide.
The rapid development of the Internet speeds up the development of cross-border e-commerce. The transaction scale of cross-border e-commerce of B2C in our country has been expanding with the development of cross-border e-commerce platform. Especially in the aspect of export cross-border, our country, as a big manufacturing country, has a rich product range and a great advantage in product cost. Coupled with the tilt of China's policies in recent years, China's B2C cross-border export electricity supplier can Rapid development, showing a continuing trend of growth. For now, has a very broad development prospects. 


\section{THE IMPACT OF B2C CROSS-BORDER EXPORT E-COMMERCE ON THE DEVELOPMENT OF CHINA'S SMES}

A. Reducing the risk faced by small and medium enterprises

Most small and medium-sized foreign trade enterprises will face problems such as financing difficulties and rising costs. If enterprises must fundamentally solve these problems, they must enter the higher value-added links in the industrial chain. B2C cross-border e-commerce can help companies to directly target end-users and get more profit with lower cost and simpler operation methods [5]. At the same time, because B2C cross-border e-commerce has realized the transaction between enterprises and individual consumers, enterprises need to transform to small orders, individualized and multi-production models, and promote the innovation ability of SMEs.

\section{B. Improving the competitiveness of SMEs}

First, cross-border e-commerce has reduced corporate financial pressures, reduced trade links, and reduced transaction costs. Moreover, B2C cross-border e-commerce provides enterprises with huge customer data. The company directly targets the final consumers. These data help SMEs to better grasp customer needs and improve product quality and service through technology upgrades. The production and service capabilities of the enterprise. At present, many SMEs conduct cross-border retail transactions on third-party platforms such as Amazon, eBay, Wish, and AliExpress. Among them, Wish focuses on mobile, and is very popular among SMEs and customers.

\section{THE DEVELOPMENT OF THE WISH PLATFORM}

Wish APP ranks first in shopping apps in 27 countries around the world, ranked 7th in the Android App Store category, and 14th in the App Store category app in USA [6]. According to Internet statistics, Wish has nearly 450 million downloads, the number of registered users has exceeded 330 million, and more than 10 million active users per day, and 500,000 new users per day. Wish's main customer base is between 16 and 30 years old. The ratio of male to female customers is $3: 7$, with $30 \%$ of male users contributing $60 \%$ of sales. In addition, according to incomplete statistics, as of November 2017, there are about 190,000 sellers on the Wish platform, of which more than $90 \%$ are from China, and most of them are SMEs.

As of June 2017, the Wish platform has a product SKU of nearly 200 million, with an average daily order volume of more than 1.1 million (the peak exceeded 3 million). The platform's customer market is mainly concentrated in Europe. Currently, the top five market share is: North America accounts for $48 \%$, Europe accounts for $34 \%$, South America accounts for $10 \%$, Asia accounts for $3 \%$, and Australia accounts for $3 \%$ [7].

According to the statistics of easy-to-select items, in 2017, the sales volume of Double Eleven was 3.05 million, and the total sales reached US\$ 25.76 million. In this year's "Black Friday" event, on the "Black Friday" day alone, the trading volume of the Wish platform reached 3.35 million, with a total turnover of 29.48 million US dollars [8]. The sales volume of each industry is shown in Figure 3.

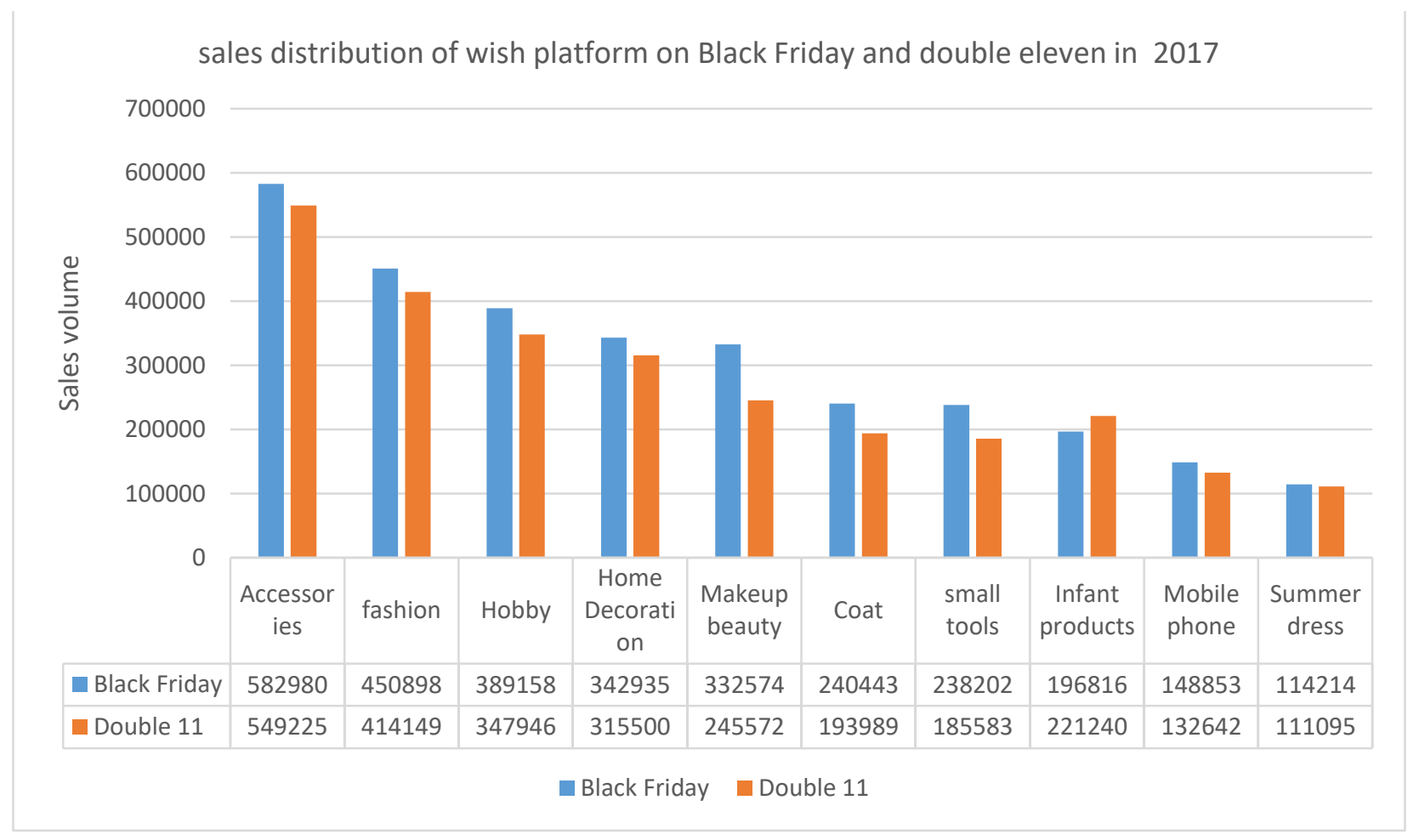

Fig. 3 Sales distribution of wish platform on Black Friday and Double-eleven day in 2017 


\section{Business model}

Wish firmly grasps the mobile terminal's "anytime, anywhere" feature, opening up a living space outside the large cross-border e-commerce platform such as Amazon and AliExpress. Wish dilutes product screening and search weights, focusing on product association recommendations. When a new user logs in on the Wish platform, Wish will push some products that are suitable for the general public, such as jewelry, T-shirts and so on. After that, Wish will track and record the user's browsing trajectory, analyze the user's usage habits, and then speculate the user's preferences, and then carry out more accurate association push. When different users open the Wish APP, the resulting page is different, and even the same user opens the page content that Wish sees at different times [9]. This is where the characteristics of Wish can be achieved by using consumer big data and intelligent algorithms to achieve precise push and form a tacit interaction with users, which greatly enhances user stickiness.

\section{Personalized recommendation system}

The biggest feature of Wish is that it is more inclined to help users find the products they like and even help users to tap potential preferences. The Wish client's launch page has a slogan called Shopping Made Fun, which reflects Wish's mission to provide a delightful shopping experience for the user.

New users can sign up and log in via social accounts like Google and Facebook. If the user selects the item type information of interest when registering, Wish will automatically filter the relevant items for the user to personally push. If the user chooses to skip this step, then in the initial product browsing, Wish will only push some general merchandise that suits the public's preferences. As the number of users is used more and more, the more user data is recorded by Wish, the better analysis and mining from this data will be used to recommend personalized products for users. A dynamic relationship between the supply platform and the user is highly compatible with the user, which greatly enhances the user experience.

\section{E. Direct purchase and settlement}

Wish uses the waterfall streaming image display method, which is similar to the traditional photo social shopping site, but in fact, the product images that Wish shows to users are the products that are best etched out by users and are interested in the user's preferences and interests. When you like the picture you like, you can click on the picture to be able to purchase the transaction directly in the station. This allows users to always have the freedom to do whatever they want, saving time in editing product information.

In the whole process of Wish's product browsing and trading, it is basically the interaction between the platform and the user, and the seller does not need to participate. Wish works with professional third-party payment software, and buyers and sellers avoid payment risks. Wish forms a closed-loop commodity trading process.

\section{F. The Advantages of Wish Platform}

Compared to Amazon, eBay, and AliExpress, Wish has a more entertaining image social networking site with a better user experience and greater user stickiness. The intelligent algorithm realizes the personalized customization of "Thousands of People" to meet the fragmentation requirements of the mobile terminal. The shopping experience on Wish is like hanging a shopping plaza on a mobile phone. Users are casually aware of what they might not know and have the potential to buy. In addition, Wish positions the customer base to young people aged 16-30 who are also major users of the mobile Internet. Based on this positioning, wish has a stronger sense of entertainment and fashion, in line with the development trend of mobile. Finally, compared to the high cost of several mainstream platforms such as Amazon, AliExpress and eBay, Wish's low threshold and zero charge are obviously more suitable for SMEs. A detailed comparison is shown in table 1.

TABLE I COMPARISON OF THE COSTS OF FOUR MAJOR B2C CROSS-BORdER PlatFormS

\begin{tabular}{|l|c|c|c|c|}
\hline & AliExpress & Amazon & eBay & Wish \\
\hline Platform costs & $10000+$ CNY & 479.88 USD & $239.4-4199.4$ USD & 0 \\
\hline Commission & $8 \%$ & $15 \%$ & $4 \%-9 \%$ & $15 \%$ \\
\hline Payback period & $3-15$ days & 14 days & $3-10$ days & 15 days \\
\hline
\end{tabular}

In addition to the $8 \%$ commission fee for the transaction amount, AliExpress charges at least RMB 10,000 per year for the technical service fee. Amazon charges a commission fee of $6 \%-45 \%$ (mostly 15\%) based on product categories, and companies also need to pay a deposit of 10-50 thousand USD, and companies pay $\$ 39.99$ a month ( $\$ 479.88$ a year) Monthly rent. eBay's fees are more complex, charging a store fee of \$239.4-4199.4 based on store grade and monthly or annual payments [10]. Compared to these three platforms, Wish only charges a $15 \%$ commission fee, and the platform does not need to pay the marketing fee to distribute traffic, which is very friendly for SMEs.

At present, these platforms tend to attract large and medium-sized product companies to settle in. The survival of SMEs in Amazon and AliExpress will be more difficult in the future. As a new generation of mobile cross-border e-commerce platform, Wish has a unique mobile UI design, focusing on the sale of small-value goods, the same size and size of sellers, is very suitable for SMEs as a breakthrough in opening up overseas markets. 


\section{THE DEVELOPMENT STRATEGY FOR THE WISH PLATFORM}

\section{A. Product selection}

In general, products with low unit prices are relatively easy to sell, and the flow conversion rate is high, which can drive the sales rate of the store, increase the activity of the store, and seize more traffic. However, such products are usually small items, and in order to reduce the cost, generally, low-cost logistics such as Wish Mail is used for distribution, and the delivery time is long. As a result, the settlement is slow, the date of arrival is long, and the profit is much lower. This is a big financial pressure for small and medium sellers. The high unit price of the product is relatively high, and the delivery time is short. Therefore, the account period is shorter. Therefore, in product selection, the best strategy is to combine high-priced products with products with low unit prices.

In addition, due to cultural differences between countries, products need to refer to Facebook, Twitter and other foreign social networking sites to upload specific products according to their preferences.

\section{B. Editing and optimization for product information}

Wish is a mobile-based app, compared to other shopping platforms, the biggest features of wish is the weakening of search functionality. Achieve thousands of people through big data and intelligent matching. So, one of the key works is to write the title and the tags. In order to be grabbed by Wish's system machine and pushed to potential consumers, the ten labels of the product are preferably a combination of long tail words and precise words, including the secondary category and tertiary category of the product, 1 to 2 product characteristic words and 1 to 2 product applicable scene words. In addition, there must be beautiful pictures and flexible display according to the screen of the mobile phone.

\section{Product promotion}

Because most of Wish's clients are from Facebook, marketing on Facebook is very important. It can be promoted on Facebook by the following methods. 1. Through Facebook, dynamically analyze potential users, group them according to user purchasing habits or preferences, and promote products in a targeted manner. 2. Register a public homepage account for your store to get fans and attention. Post discounts and offers. 3. Using the interest targeting in the Facebook advertising system, you can locate many directions, such as the user's social role, preferences, gender, age, country and other information, in order to find users with matching interests, to achieve accurate promotion products.

\section{SUMMARY}

This paper first analyzes the development status of China's B2C cross-border export e-commerce and its impact on SMEs and its significance. Then it analyzes the development status, advantages and prospects of the Wish platform. Finally, combined with my practical experience in the operation of the Wish platform, we have put forward my opinions and suggestions on how to operate on the Wish platform, and hope to help SMEs to understand the rules and techniques of platform operation, and help them develop better in the early stages of operation.

\section{ACKNOWLEDGEMENT}

This work was partly supported by Key Projects of Science and Technology Plan in Fujian Province under Grant 2016H0029; Fujian Social Science Federation Project No.FJ2018B022; Key Projects of Quanzhou Technology Bureau Nos. 2012Z102, $2013 Z 123$.

\section{REFERENCES}

[1] Ali Research Institute. 2016 China Cross-border E-Commerce Development Report [EB/OL].http://www.199it.com/archives/513239.html, 2016-9-2.

[2] Ge Manyang. Research on the development of cross-border import retail e-commerce from the perspective of consumers and its countermeasures [J]. Economic and Trade Practice, 2017, (10): 35-36.

[3] Chen Hua. Analysis: The basic standards of cross-border e-commerce model competition and evaluation [EB/OL].http://b2b.toocle.com/detail--6285687.html, 2015-10-21.

[4] NetEase News. Global cross-border e-commerce Wish won the F-round investment of the optical capital [EB/OL].http://news.163.com/17/0517/00/CKJKHTIT00018AOP.html, 2017-5-17

[5] [5] Wang Xiaofei. Analysis of the role of cross-border e-commerce in the development of small and medium-sized foreign trade enterprises [J]. Modern Business, 2017, (3): 22-23.

[6] Ding Wei. Research on the impact of cross-border e-commerce on the competitiveness of SMEs [D]. Capital University of Economics and Business, 2016.

[7] Wang Wei. Analysis and Enlightenment of Marketing Strategy of Amazon and Wish in Small and Medium-sized Cross-border Export E-commerce [J]. New Marketing, 2017, (8): 40-41.

[8] Lao Wei. The eight core elements of the Wish platform operation [EB/OL].https://mp.weixin.qq.com/s? biz=MzA5NTAwMTIwOQ== $\& \mathrm{mid}=400659112 \& \mathrm{idx}=5 \& \mathrm{sn}=28 \mathrm{f} 49 \mathrm{c0}$ efdd6b261b576b2a835e78d $8 \mathrm{a} \# \mathrm{r}$ d.2015 -11-26.

[9] Li Xueqi. Analysis of the Impact of B2C Cross-border E-commerce Platform on China's Foreign Trade-Taking Alibaba AliExpress as an Example [D]. Capital University of Economics and Business, 2016.

[10] PR Newswire. Global Cross-Border B2C E-Commerce 2017[J].PR Newswire US, 2017. 